\title{
Review of Electrochemical Capacitors Based on Carbon Nanotubes and Graphene
}

\author{
Jian Li* Xiaoqian Cheng, Alexey Shashurin, Michael Keidar \\ Department of Mechanical and Aerospace Engineering, The George Washington University, Washington DC, USA \\ Email: \{lijian, keidar\}@gwu.edu
}

Received May 20, 2012; revised June 15, 2012; accepted July 20, 2012

\begin{abstract}
Electrochemical capacitors, which can store large amount of electrical energy with the capacitance of thousands of Farads, have recently been attracting enormous interest and attention. Carbon nanostructures such as carbon nanotubes and graphene are considered as the potentially revolutionary energy storage materials due to their excellent properties. This paper is focused on the application of carbon nanostructures in electrochemical capacitors, giving an overview regarding the basic mechanism, design, fabrication and achievement of latest research progresses for electrochemical capacitors based on carbon nanotubes, graphene and their composites. Their current challenges and future prospects are also discussed.
\end{abstract}

Keywords: Electrochemical Capacitors; Ultracapacitors; Supercapacitors; Carbon Nanotubes; Graphene

\section{Introduction}

Electrochemical capacitors (EC) are rechargeable electrochemical energy storage devices, which can store much larger amount of electrical energy with the capacitance of thousands of Farads in the interfaces between electrodes and electrolyte. Compared with other energy storage devices, such as batteries, EC can offer great advantages of high power capability, high rates of charge and discharge, high cycle life, flexible packaging and low weight. The invention of EC aims to bridge the critical performance gap between higher energy density of battery and high power density of conventional electrolytic capacitor [1-6]. As such, EC can facilitate and benefit various applications, for instance, portable electronics, digital communications, hybrid electric vehicles, and so forth [7-10].

In principle, EC stores the electrochemical energy in two different ways [11]. The first storage mechanism is non-Faradic, that is, only ion adsorption takes place between the interfaces of electrodes and electrolyte, therefore the storage of electric energy is electrostatic. According to the storage function, this category of EC is dubbed as electrical double layer capacitors (EDLC), or ultracapacitors. Because the charging and discharging of such ultracapacitors involve no chemical reactions, they have an unlimited degree of cyclability in theory. The other category of EC is based on the Faradic processes, similar to what take place in a battery, i.e. the energy

${ }^{*}$ Corresponding author. storage is achieved by electron transfer that follows reduction-oxidation (redox) reaction in electro-active materials. This kind of EC is called pseudo-capacitors or supercapacitors. The terms ultracapacitors and supercapacitors are not distinguished strictly at the beginning of invention; they both have very high level of capacitance and constitute the two categories of EC. However, in order to alleviate the confusion over nomenclature in this paper, it is better to emphasize that ultracapacitors are referred to the symmetric, electrostatic EC entirely based on carbon nanostructures while supercapacitors are used for the class of asymmetric and Faradic EC, which contains metal oxide or conducting polymer [12].

To emerge as the revolutionary energy storage devices, EC should possess the capability of higher energy density, while maintaining lower cost for large-scale production in industry. Essentially, the performance of EC is depending on the electro-active materials served as electrodes and collectors. So far, the various carbon-based materials, including activated carbon, ordered mesoporous carbon, carbon nanotubes (CNT), graphene and their composites, are intensively utilized for the fabrication of EC. Among these nanomaterials, CNT and graphene are the rising nanomaterials for electronic and energy storage devices due to their highly accessible surface area, nanoscale structure and good electrical conductivity since they were discovered [13-15]. Thus the primary focus in this paper will be on the recently developed progresses of EC based on CNT, graphene and their composite in laboratory and industry. The paper is organized as follows: 
principle and mechanism of charge storage are firstly described in terms of different types of EC in Section 2. The fabrication methods and properties of EC based on CNT, graphene or their mixture are described in Section 3 and sequentially the comparison with commercial product is presented. The challenges and future research prospects are summarized in Section 4.

\section{Principle and Mechanism of Charge Storage}

According to the energy storage mechanism and electrode materials, the major EC can be classified in following three types: carbon-based ultracapacitors, metaloxides-based supercapacitors and conducting-polymersbased supercapacitors.

\subsection{Electrical Double Layer Capacitors (Ultracapacitors)}

The first category is non-faradic EDLC, namely ultracapacitor, where the electrodes are only based on carbon materials with large SSA, including activated carbon [16], CNT [17], and graphene [18]. They store energy at the interface of electrolyte and electrodes through reversible ion adsorption onto surface of the electro-active carbon materials, thus charging double-layer capacitance. This mechanism was firstly defined by Helmholtz [19]. The major difference compared with other EC is that the charge is stored only on the surface of carbon where no redox reaction is involved in the energy storage processes.

The capacitance can be described as:

$$
C=\frac{\varepsilon A}{d}
$$

where $\varepsilon$ is the electrolyte dielectric constant, $A$ is the surface area accessible to ions and $d$ is the distance from ions to the pore surface of carbon electrodes on the order of angstroms. According to the equation, two approaches can be taken to enhance the charge storage of EDLC effectively: increasing the SSA and reducing distance between ions and the carbon surface. Surface area is generally increased by the development of porosity in the bulk of carbon materials [20]. In industry, the widely used approach to increase surface area is to carry out surface treatment in carbon materials. On the other hand, the pore size inside the electrodes can determine the distance between ions and the carbon surface, and further influence the specific capacitance of EDLC [21]. Three pore groups can be classified according to the size distribution: micro, meso and macro pores with diameters less than 2 $\mathrm{nm}$, between 2 and $50 \mathrm{~nm}$, and more than $50 \mathrm{~nm}$, respectively [22]. The traditional view anticipated that meso pores with a size close to twice that of the solvated ions lead to the maximum specific capacitance. In addition, from the meso pores to the pore size of $1 \mathrm{~nm}$, the specific capacitance decreases simultaneously with the decrease of the pore size [23]. However, the current research showed when the pore size is less than $1 \mathrm{~nm}$, the specific capacitance dramatically increases, contrary to what was expected in traditional theory [24,25]. According to this view, CNT and graphene are promising candidates for electrodes of EC because of their novel nanoscale size and controllable size distribution.

\subsection{Metal-Oxides-Based Supercapacitors}

The second type is redox-based supercapacitors, where transition metal oxides are utilized for electrodes owing to fast and reversible redox reactions at the surface of electro-active materials. The widely used metal oxides nanostructured materials involve $\mathrm{MnO}_{2}$ [26,27], $\mathrm{RuO}_{2}$ [28,29], $\mathrm{MoO}_{3}[30], \mathrm{Co}_{3} \mathrm{O}_{4}$ [31], $\mathrm{VOx}$ [32], and so forth.

To explain the mechanism of metal oxides in EC system, $\mathrm{MnO}_{2}$ is taken as an example. There are two mechanisms proposed for the charge storage in $\mathrm{MnO}_{2}$ electrodes. The first one is based on intercalation of alkali metal cations $(\mathrm{C}+)$ such as $\mathrm{Li}^{+}, \mathrm{Na}+, \mathrm{K}+$ or protons $(\mathrm{H}+)$ during reduction, and as well extraction of cations upon oxidation $[33,34]$.

$$
\mathrm{MnO}_{2}+\mathrm{e}^{-}+\mathrm{C}^{+} \leftrightarrow \mathrm{MnOOC}
$$

or

$$
\mathrm{MnO}_{2}+\mathrm{e}^{-}+\mathrm{H}^{+} \leftrightarrow \mathrm{MnOOH}
$$

The second mechanism is a surface process, which involves the adsorption and desorption of alkali cations or protons [35]. Therefore, in order to obtain considerable capacitance for this type of pseudo-capacitor, it is believed to combine the redox reaction of metal oxides and the large surface area of electro-active carbon materials as well. Additionally, metal oxides usually have a high electrical resistance, which might result in a low power density, and thus need CNT or graphene to offset the drawback in electrical properties.

\subsection{Conducting-Polymers-Based Supercapacitors}

The third category is also pseudo-capacitor based on faradic reactions, but the electrode materials are electronically conducting polymers [36], or their composites such as polypyrrole (PPy) [37,38], polyaniline (PANi) [39,40], poly(3,4-ethylenedioxythiophene) (PEDOT) [41], and so on. This type of conducting polymers has a relatively high conductivity, and a relatively low cost compared to carbon-based electrode materials [42]. Faradic reactions of conducting polymer are electrochemical doping processes, which are extraction of electrons from 
the polymer backbone through the external circuit and intercalation of an anion from solution into the polymer film to balance the positive electronic charge. In order to have the greatest potential energy and power densities, the supercapacitors contain one positively charged ( $\mathrm{p}$-doped) and one negatively charged (n-doped) conducting polymer electrode; however, it is believed that the mechanical stress on conducting polymers limits the stability of the pseudo-capacitors during cycling redox reactions $[43,44]$. This process reduces the cycling stability and influences the development of conducting polymer pseudo-capacitors.

\section{Fabrication and Properties of EC}

In this section, the fabrication methods and the important parameters of EC will be presented based on different carbon nanomaterials according to the recent publication.

Specific energy of EC is the amount of energy stored per unit mass, and is dependent on SSA of the electroactive electrode materials and the range of operating voltage. Specific power is the rate at which the energy is converted per unit mass, and is greatly affected by the structure of the electro-active materials that governs the transport rate of electrolyte ions to and from the materials surface. Figure 1 shows the comparison of the performance of batteries, capacitors and EC reviewed in this sec- tion in a Ragone plot where their specific power and energy are displayed. Regarding the measurement technique, there are two major configurations. The first one is the measurement in a symmetric two-electrode cell configuration. The other one is individual electrode measurements in a three-electrode cell configuration. If the redox peaks in the positive and negative electrodes of the two electrode cell do not take place at the same value of the applied voltage, the difference by the factor of 3 or more between such measurements. For a comparison of different electro-active materials, it is more reasonable to compare the values of specific capacitance obtained in two-electrode cells, because it provides the most accurate measure of a material's performance for EC $[45,46]$. Hence, only reference results obtained in a two-electrode system were compared in this paper.

\subsection{CNT}

CNT are promising active materials for flexible electrodes of electrochemical energy storage devices, due to the high surface area, good electrical conductivity and mechanical strength, good corrosion resistance and chemical stability, low mass density. There are two type of CNT according to the physical structures: single-walled carbon nanotubes (SWCNT) and multi-walled carbon nanotubes (MWCNT). Compared with MWCNT, SWCNT

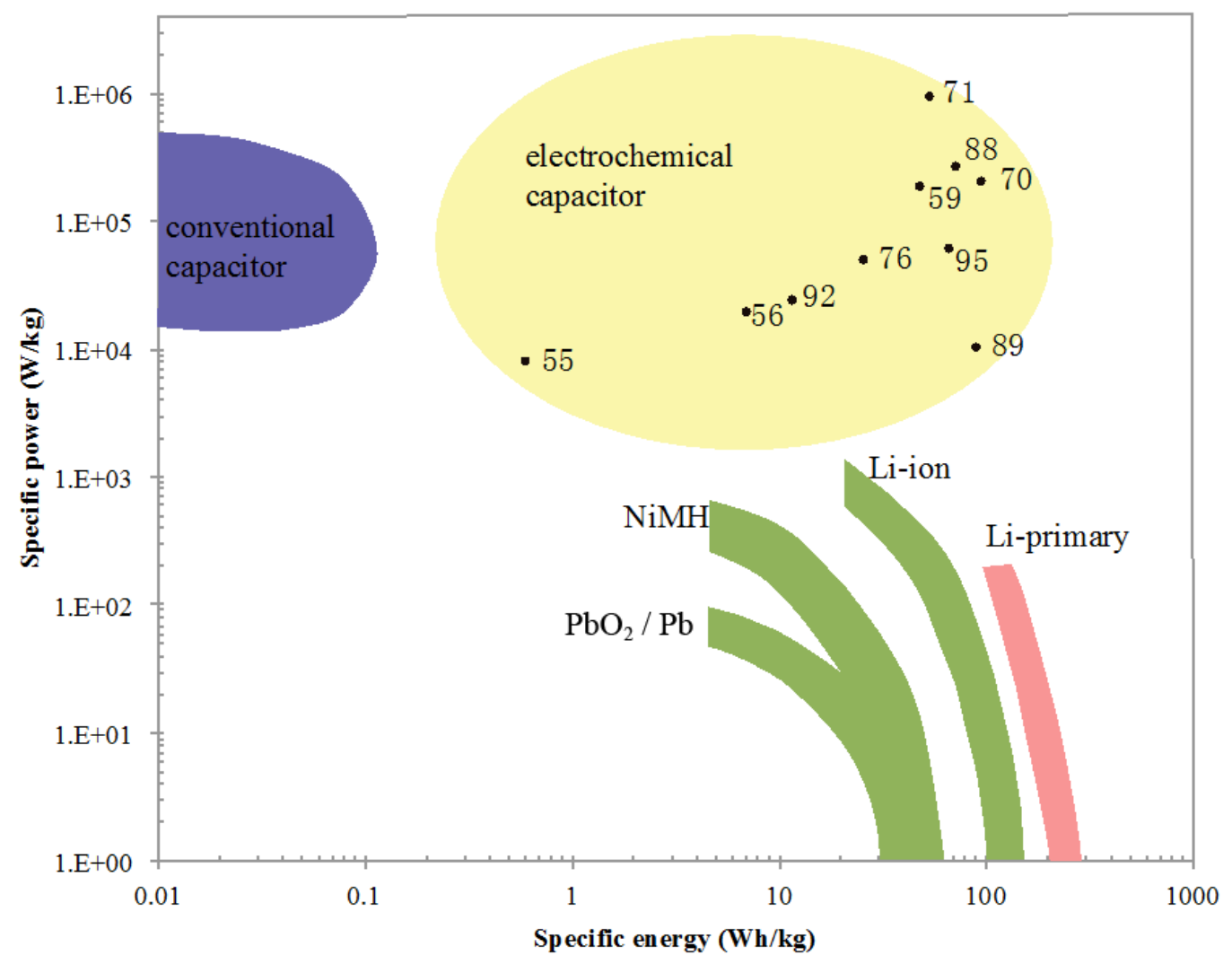

Figure 1. Ragone plot for electrochemical energy storage devices: batteries, capacitors and electrochemical capacitors. 
have larger SSA accessible to ions in the electrolyte. For SWCNT-based electrodes, a maximum specific capacitance of $180 \mathrm{~F} / \mathrm{g}$ was found in literature, whereas MWCNT-based electrodes only have the specific capacitance in the range of $4-137 \mathrm{~F} / \mathrm{g}$.

In order to realize the promising features that CNT possess, three major approaches are utilized to create a CNT thin film served as electrodes, including vacuum filtration [47], wire wound rod coating [48], and electrophoretic deposition [49].

\subsubsection{Vaccuum Filtration}

The vacuum filtration method is used for a freestanding CNT film which is proper to integrate current collector and electrode in a EC system. In this method the CNT suspension is filtered through the pore size in the micrometer range, i.e., $0.45 \mu \mathrm{m}$ or $0.2 \mu \mathrm{m}$ [50-52]. The vacuum or lower pressure is created to facilitate CNT suspension through the filter. As the liquid suspension passes through the filter pores, CNT are trapped on the surface to form a random oriented network. Two different procedures could be carried out for the next step. The thin film of CNT conjunct with filters can directly serve as the integration of electrode and separator in an electrolyte. In the case that only CNT thin film is needed, the nitrocellulose filter also can be easily removed by the chemical treatment such as immersing in acetone $[53,54]$.

Preparing the electrodes of ultracapacitor by vacuum filtration method, Niu et al. [55] have reported that MWCNT reached the specific capacitance of $113 \mathrm{~F} / \mathrm{g}$ and a specific power of $8 \mathrm{~kW} / \mathrm{kg}$ at a specific energy of 0.56 $\mathrm{Wh} / \mathrm{kg}$ in a $\mathrm{H}_{2} \mathrm{SO}_{4}$ electrolyte. According to the relationship between distribution of pore diameter of SWCNT thin film and the temperature in heat treatment, An et al. [56] reported a maximum specific capacitance of $180 \mathrm{~F} / \mathrm{g}$ with the treatment temperature of $1000^{\circ} \mathrm{C}$. In a solution of $7.5 \mathrm{~N} \mathrm{KOH}$, the specific power and specific energy of

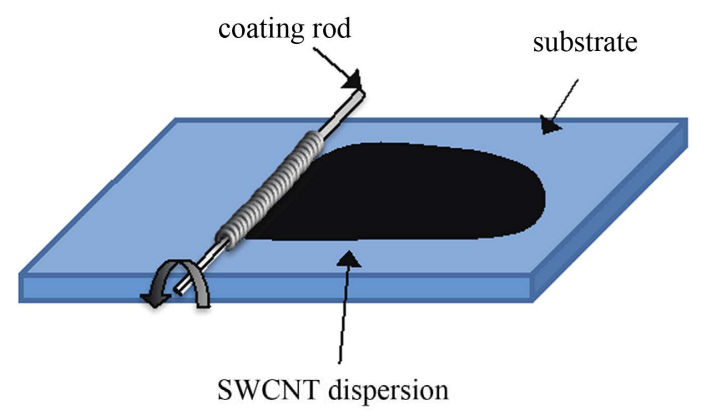

(a) the ultracapacitor based on SWCNT are $20 \mathrm{~kW} / \mathrm{kg}$ and 7 $\mathrm{Wh} / \mathrm{kg}$, respectively.

\subsubsection{Wire Wound Rod Coating}

The wire wound rod coating process is utilized to fabriccate uniform CNT thin films for high volume manufacturing shown in Figure 2(a). The mechanism of this technique is that space gaps between wire diameters can be used to control the volume of fluid on a surface of paper. In addition, the surface tension of the deposited fluid can flatten the surface of CNT deposit [57].

By this technique, Hu et al. [58] prepared flexible SWCNT ultracapacitor, where electrodes and separators are integrated into single sheets of commercial paper. A specific capacitance of $33 \mathrm{~F} / \mathrm{g}$ and a high specific power of $250 \mathrm{~kW} / \mathrm{kg}$ were achieved with an organic electrolyte. In order to reduce the sheet resistance of electrodes, $\mathrm{Hu}$ et al. [59] also combined silver nanowire and SWCNT thin films together by the rod coating method, achieving a specific capacitance of $200 \mathrm{~F} / \mathrm{g}$. The flexible paper coating with SWCNT thin film has great potential to replace metallic current collector in lithium battery, due to the advantage of light weight, high conductivity and low cost.

\subsubsection{Electrophoretic Deposition}

In electrophoretic deposition (EPD) setup, voltage potential was applied to two electrodes to move charged particles of the coating materials from a solution illustrated in Figure 2(b). To make the process effective, the electrodes and the deposition particles in suspension should be electrically conductive. Hence functionalization of CNT by acid or other solution is necessary to make them electrically charged before the EPD processes. Among these fabrication methods, EPD has been found to yield the lowest surface roughness of CNT thin film, minimal surface resistance of CNT electrode and excellent materials utilization $[60,61]$.

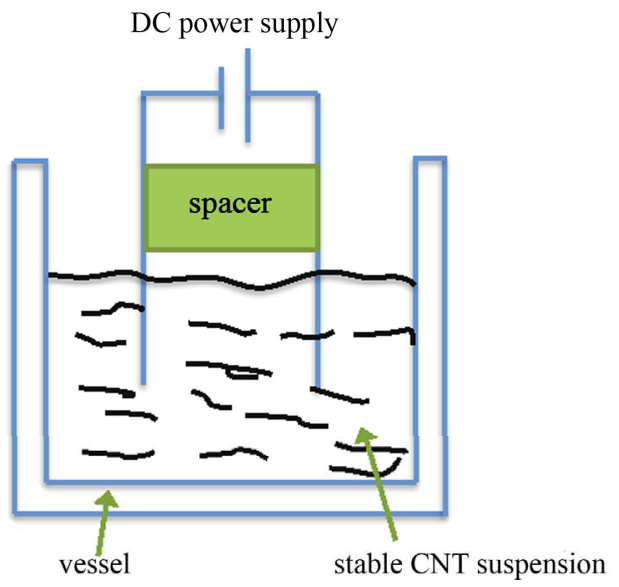

(b)

Figure 2. (a) Schematic diagram of wire wound rod coating method; (b) Schematic graph of electrophoretic deposition method. 
By EPD technique, Du et al. [62] reported the fabrication of MWCNT thin film as electrodes for ultracapacitors, which have a very small equivalent series resistance of 830 milli-ohm and superior frequency response due to improved adherence of EPD coatings. The specific capacitance and specific power of the ultracapacitor are 21 $\mathrm{F} / \mathrm{g}$ and $20 \mathrm{~kW} / \mathrm{kg}$, respectively.

\subsubsection{Super-Aligned CNT}

Super-aligned CNT conventionally stand for the entire CNT that have the same orientation perpendicular to the substrate $[63,64]$. The most attractive approach to obtain aligned CNT is direct growth by chemical vapor deposition [65] with an external force, e.g., an electric field, the gas flow or interactions with the substrate surface such as sapphire which can provide high density and perfect alignment $[66,67]$. It shows that uniform nanotubes arrays fabricated on substrates can be transferred directly as a thin film for electronics applications [68]. There are several advantages to fabricate electrodes of EDLC by aligned CNT. Firstly, the CNT in uniform orientation can facilitate ion transport and make great contribution to high power capability. Secondly, well-controlled microscale pores can be introduced due to the structural features of super-aligned CNT [69]. Lastly, super-aligned CNT have superior electrons transport and less electrical resistance than the CNT thin film with random network, thus making them benefical for the electrodes of EC.

Izadi et al. [70] used the super-aligned SWCNT as electrodes of ultracapacitor to achieve the lowest possible amount of impurities and a very high specific surface area of $1300 \mathrm{~m}^{2} / \mathrm{g}$. The shear transfer technique by glass slides was utilized to make the aligned SWCNT parallel to the platinum current collectors of ultracapacitor. The combination of high surface area and super-aligned structure enabled a high specific capacitance of $160 \mathrm{~F} / \mathrm{g}$ in organic electrolyte. Kim et al. [71] tested ultracapacitors made of aligned CNT in ionic liquids electrolyte and nonaqueous organic electrolyte. The specific capacitance of ultracapacitor in ionic liquid was $160 \mathrm{~F} / \mathrm{g}$ and the specific power reached very high value of $990 \mathrm{KW} / \mathrm{kg}$ because of the fast ion transport of the super-aligned CNT.

\subsubsection{CNT Composite}

Although EDLC can deliver high specific power, specific energy is still low so that it limits the usage of ultracapacitor to few seconds. Increasing the specific energy of EC would lead to extend discharge time and widen the application market. On the other hand, the redox-based capacitors which only contain metal oxides can reach high specific energy and superb specific capacitance, e.g. $1300 \mathrm{~F} / \mathrm{g}$ of $\mathrm{MnO}_{2}$ capacitor in aqueous electrolytes [72], however the low electrical conductivity, poor compatibility with organic electrolytes, and short cycle life have limited their practical application. To take the advantages of reversible ions adsorption of carbon nanostructures and faradic reaction of metallic oxidation, the hybrid supercapacitors constituted by the combination of carbon nanostructures and metal oxides have been extensively studied recently [73-75].

Chen et al. [76] reported the fabrication of flexible asymmetric supercapacitors constituted by $\mathrm{MnO}_{2}$ nanowire/SWCNT hybrid films as the positive electrode and $\mathrm{In}_{2} \mathrm{O}_{3}$ nanowire/SWCNT hybrid films as the negative electrode illustrated in Figure 3. This asymmetric design allowed the devices to work in the potential window of 2 volt. In addition, the optimized hybrid nanostructured supercapacitors exhibited a superior device performance with specific capacitance of $184 \mathrm{~F} / \mathrm{g}$ and high specific energy of $25.5 \mathrm{Wh} / \mathrm{kg}$.

\subsection{Graphene}

Theoretically SWCNT have an limit SSA of $1300 \mathrm{~m}^{2} / \mathrm{g}$ [70], and also the high cost for mass production of highquality CNT is a challenge for the commercialization of CNT-based EC. Graphene flakes and sheets have shown a high electrical conductivity, a high theoretical SSA of $2630 \mathrm{~m}^{2} / \mathrm{g}$ and a very high intrinsic electrical conductivity in plane as well as high mechanical strength and chemical stability comparable with or even better than CNT [77,78]. Generally speaking, there are four approaches to synthesize graphene for the application of $\mathrm{EC}$, that is, mechanical exfoliation from bulk graphite [15], arc discharge [79], chemical vapor deposition and epitaxial growth, $[80,81]$ and reduction of graphite oxides [82]. The synthesis of graphene by exfoliation of graphite is not in large scale so that it is only suitable for fundamental study so far. We will review arc discharge method to synthesize graphene in Section 3.3. Here we mainly discuss the application of graphene in EC by the latter two approaches and also consider the composites of graphene with metal oxides or conducing polymer for supercapacitors.

\subsubsection{Chemical Vapor Deposition}

Chemical vapor deposition is a promising method to synthesize carbon nanostructures including CNT and graphene. The mechanism is to pyrolyze hydrocarbon resources such as methane or acetylene at well-controlled high temperature. Upon the annealing process, the solubility of carbon in the catalyst metal decreases and the carbon nanostructures can precipitate on the catalyst surface. Most often, nickel and copper films are used as growth substrate for graphene [83-85].

Yoo et al. [86] fabricated an ultrathin ultracapacitor based on continuous single and few-layer graphene films by chemical vapor deposition technique on polycrystal- 
line $\mathrm{Cu}$ foils using liquid precursor hexane. The in-plane design was straightforward to implement so that the surface of each graphene layer was exploited efficiently for energy storage exploits efficiently. The performance of the device was examined in both $\mathrm{PVA} / \mathrm{H}_{3} \mathrm{PO}_{4}$ polymergel electrolyte and an aqueous $1 \mathrm{M} \mathrm{H}_{2} \mathrm{SO}_{4}$ electrolyte. The specific capacitance reaches high value of $247 \mathrm{~F} / \mathrm{g}$.

\subsubsection{Chemical Reduction of Graphite Oxides}

Graphite oxide is a compound of carbon, oxygen and hydrogen in variable ratios, which can be obtained by oxidation of graphite in the presence of strong acids and oxidants. The synthesis method is to utilize a mixture of $\mathrm{H}_{2} \mathrm{SO}_{4}, \mathrm{NaNO}_{3}$, and $\mathrm{KMnO}_{4}$ as oxidizers, developed by
Hummers et al. [87] in 1957 and still widely used nowadays. The great advantage of this approach is scalable, affording high-volume production, and versatile in chemical functionalization.

Zhu et al. [88] improved the graphene synthesis technique and reported a simple activation with $\mathrm{KOH}$ of microwave exfoliated graphite oxides and thermally exfoliated graphite oxides to achieve SSA around $3100 \mathrm{~m}^{2} / \mathrm{g}$. The specific capacitance is $200 \mathrm{~F} / \mathrm{g}$ in organic electrolyte, which was the highest value of ultracapacitor only based on graphene in the organic electrolyte in 2011. For the packaged cell, the specific power and specific energy were $75 \mathrm{KW} / \mathrm{Kg}$ and $20 \mathrm{Wh} / \mathrm{Kg}$, respectively. Liu et al. [89] proposed a method to obtain very high specific energy
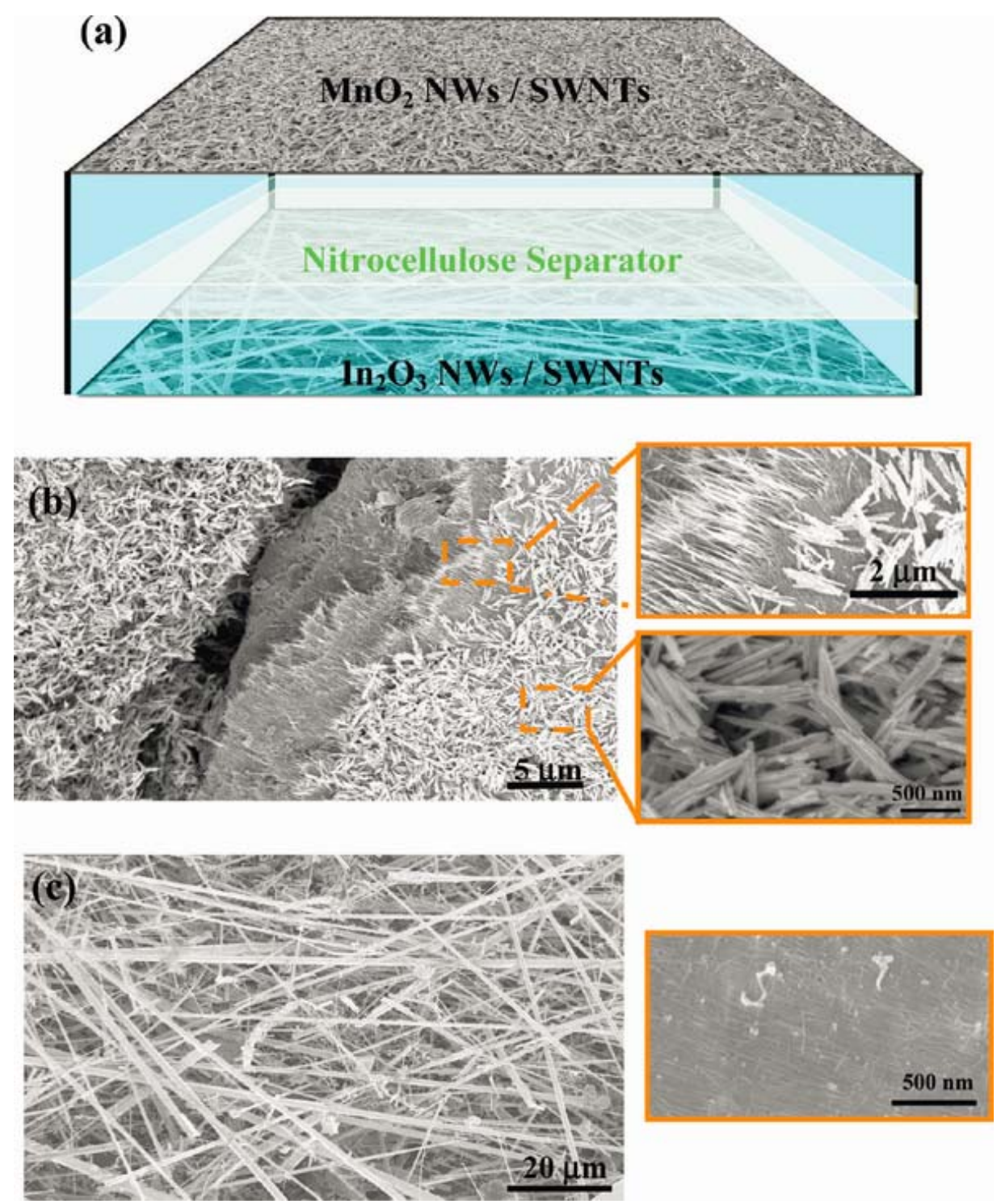

Figure 3 (a) Schematic diagram of the supercapacitor composed with a $\mathrm{MnO}_{2}$ nanowire/SWCNT hybrid film as a cathode electrode and $\mathrm{In}_{2} \mathrm{O}_{3}$ nanowire/SWCNT hybrid film as an anode electrode; (b) The morphology of $\mathrm{MnO}_{2}$ nanowire/SWCNT hybrid film by scanning electron microscope (SEM); (c) The SEM image of as-fabricated $\operatorname{In}_{2} \mathrm{O}_{3}$ nanowire/SWCNT hybrid film. Reprinted with permission from reference [76]. Copyright 2010 American Chemical Society. 
by utilizing intrinsic surface capacitance and surface area of single-layer curved graphene. The specific energy of the graphene-based ultracapacitor was tested as 85.6 $\mathrm{Wh} / \mathrm{kg}$ at room temperature and $136 \mathrm{Wh} / \mathrm{kg}$ at $80^{\circ} \mathrm{C}$ in an ionic liquid, comparable to specific energy of $\mathrm{Ni}$ metal hydride battery.

\subsubsection{Laser Reduction of Graphite Oxides}

In order to avoid the restacking of graphene sheet during the chemical treatment of graphite oxides, a strategy to produce graphene electrodes through a solid-state approach was proposed [90]. Compared with chemical reduction, the method using infrared laser to produce graphene-based materials is more facile, cheap, and environment-friendly. Notably, it is applicable for the fine patterning of graphene sheet and has the potential to simplify the manufacturing process of devices

El-Kady et al. [91] carried out the processes of laser reduction of graphite oxide films to graphene directly by a standard LightScribe DVD drive shown in Figure 4. Initially, a thin film of graphite oxides dispersed in water was drop-cast onto a flexible substrate. After laser reduction, the graphene-based materials can be used directly as electrodes of ultracapacitors without binders or current collectors. The SSA of graphene by this approach was measured as $1520 \mathrm{~m}^{2} / \mathrm{g}$. In addition, the ultracapacitor offered a specific capacitance of $265 \mathrm{~F} / \mathrm{g}$ in an organic electrolyte with a wider operating voltage window of $3 \mathrm{~V}$.

\subsubsection{Graphene Composites}

Graphene is also a good candidate combining with metal oxides and conducting polymer to provide higher specific energy and electrical conductivity for the electrodes of supercapacitors.

Cheng et al. [92] utilized electrophoretic deposition method to mix $\mathrm{MnO}_{2}$ nanostructures with graphene film by a cyclic voltammetric technique $(250 \mathrm{mV} / \mathrm{s})$. The graphene-based supercapacitors showed a higher specific capacitance due to the fact that the graphene can physiccally adapt different electrolyte ions, leading to a higher accessibility of electrolyte ions and also a more effective use of the specific surface area. The specific capacitance was measured as $245 \mathrm{~F} / \mathrm{g}$ for graphene thin film and 328 $\mathrm{F} / \mathrm{g}$ for $\mathrm{MnO}_{2}$-coated graphene in a $1 \mathrm{M} \mathrm{KCl}$ aqueous electrolyte solution. Also, the specific energy of $\mathrm{MnO}_{2}-$ coated graphene was $11.4 \mathrm{Wh} / \mathrm{kg}$ and the specific power was $25.8 \mathrm{~kW} / \mathrm{kg}$.

$\mathrm{Wu}$ et al. [93] reported the supercapacitors based on composite films of graphene and PANI conducting polymer. The composite film has a layered structure, and PANI polymer was sandwiched between chemicallyreduced graphene sheets. After treatment with $\mathrm{HCl}$ solution, the PANI component in the film can be re-doped. Then the specific capacitance was measured as $210 \mathrm{~F} / \mathrm{g}$ in a $1 \mathrm{M} \mathrm{H}_{2} \mathrm{SO}_{4}$ electrolyte and the composite film showed a good stability so that after 800 charging/discharging cycles the high capacitance was maintained due to the synergic effect of both components.

\subsection{CNT and Graphene Composite}

Composite materials of CNT and graphene have been described in recent years to establish synergistic effects between these two different carbon nanostructures both having unique electronic, thermal and mechanical properties [94]. Another advantage of this hybrid structures is that CNT can work as the spacer between graphene sheets preventing the re-stack of graphene, and thus enhance the performance of electrodes based on carbon nanostructures.

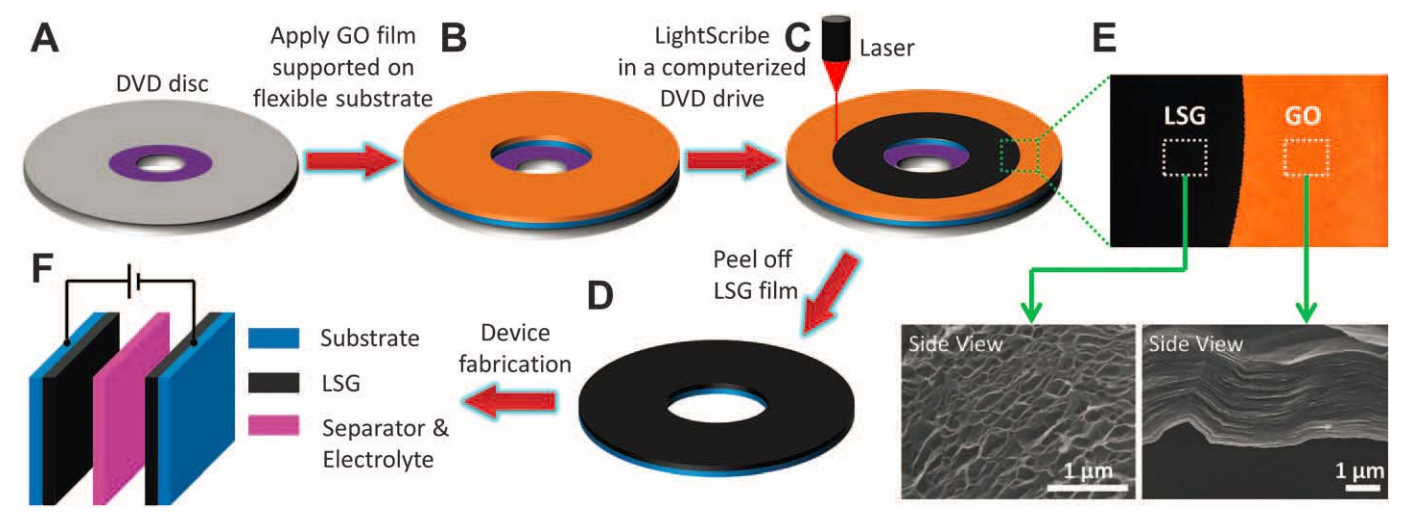

Figure 4 Schematic diagram of the fabrication of laser-scribed graphene-based electrochemical capacitors. ((A) to (D)) A graphite oxide film supported on a flexible substrate is placed on top of a LightScribe-enabled DVD media disc, and a computer image is then laser-irradiated on the graphite oxide film in a computerized LightScribe DVD drive; (E) As shown in the photograph, the graphite oxide film changes from golden brown color to black as it reduced to laser-scribed graphene. The low-power infrared laser changes the stacked GO sheets immediately into well-exfoliated few-layered laser-scribed graphene (LSG) film, as shown in the cross-sectional SEM images; (F) A symmetric EC is constructed from two identical LSG electrodes, ion-porous separator, and electrolyte. From reference [91], reprinted with permission from AAAS. 


\subsubsection{Wet Solution}

Cheng et al. [95] fabricated the electrodes of SWCNT and graphene in wet solution method. The SWCNT and graphene were first dispersed separately in ethanol. Then the suspensions passed through a microporous filter paper by vacuum filtration. Sequentially, the graphene and CNT composite film was prepared by mixing graphene and CNT by sonication in ethanol. Due to the effect of SWCNT, the specific capacitances of the composite films were tested as $291 \mathrm{~F} / \mathrm{g}$ in $1 \mathrm{M} \mathrm{KCl}$ aqueous electrolyte and $201 \mathrm{~F} / \mathrm{g}$ in an organic electrolyte.

\subsubsection{One-Step Synthesis in Arc}

Anodic arc discharge is one of the most practical and efficient methods to synthesize various carbon nanostructures [96]. A great progress of improving the controllability and flexibility of carbon nanostructures growth in arc discharge was made by introducing mag-netic field according to the strong magnetic responses of arc plasmas [97]. It demonstrated that the magnetically-enhanced arc discharge can narrow the diameter distribution of metallic catalyst particles and carbon nanotubes, increase the length of SWCNT, as well as change the ratio of metallic and semiconducting carbon nanotubes [98-100]. In light of the introduction of magnetic field in arc, our research group presented an approach to synthesize the composite production of carbon nanotubes and graphene simultaneously in a non-uniformed magnetically-enhanced arc discharge, for the purpose of utilization of excellent properties of SWCNT and graphene together [79,101,102].

The paper-based electrodes of ultracapacitor were fabricated by wire wound rod coating method with the ink of the composites and exhibited advantage in contrast to the thin electrodes only made from SWCNT synthesized without magnetic field. The sheet resistance of composite film of SWCNT and graphene was much lower than that of film made from SWCNT. The specific capacitance of ultracapacitor based on SWCNT and graphene composite in a $\mathrm{KOH}$ electrolyte was tested as $110 \mathrm{~F} / \mathrm{g}$, which is larger than that of ultracapacitor based on SWCNT of 40 $\mathrm{F} / \mathrm{g}$ in the same conditions [103].

In addition to looking at research values it can also be useful to have an understanding of the best in class commercial devices that are available on the market today. Commercial devices by necessity have typically undergone extensive durability, reliability and characterization testing to ensure that the product has a useful life and will meet or exceed the expectations of customers. Although lower than research values, the values of commercial EC as shown in Table $\mathbf{1}$ below are also a good benchmark for what is achievable in a repeatable large-scale production environment.

\section{Challenges and Future}

In this paper, we reviewed the current technology of charge storage, and highlighted the latest fabrication and achievement of EC in terms of different carbon nanostructures including CNT and graphene. The carbon nanostructures represent very exciting materials for EC as they possess the excellent properties of large SSA, good conductivity as well as fast ion transportation for sufficient electrochemical reactions at their interfaces. Supercapacitors, where very fast faradic redox reactions take place in electrode material, have higher energy density and specific capacitance than ultracapacitor. But the great cyclic stability of ultracapacitors makes them ideal for the applications which need stable and large power output. Regarding the materials of electrode, super-aligned CNT facilitate the ion transport, which can

Table 1. The list of current commercial electrochemical capacitors with high performance.

\begin{tabular}{cccccccc}
\hline Company & Device name & Country & Electrode & Electrolyte & Voltage (V) & ESR (m 2$)$ Capacitance (F) \\
\hline AVX & BestCap & USA & carbon & polymer & $3.6-16$ & $25-600$ & $0.068-1$ \\
Cap XX & Super capacitor & Australia & & & $2.3-5.5$ & $14-200$ & $0.075-2.4$ \\
Cooper & PowerStor & USA & & & $2.5-5$ & $25(\mathrm{~min})$ & $0.22-50$ \\
ELNA & DYNACAP & USA & activated charcoal & organic solvent & $2.5-5.5$ & & $0.22-100$ \\
ESMA & Capacitor modules & Russia & nickel hydroxide/AC & alkaline & $12-52$ & $100-100 \mathrm{k}$ \\
Kold Ban & Kapower & USA & nickel/carbon & KOH & $4-16$ & & $1-3000$ \\
Maxwell & Ultracapacitor & USA & & & $2.5-125$ & $0.29-700$ & 100 \\
NEC & Super capacitor & Japan & activated carbon & diluted sulfuric acid & $24(\max )$ & 1000 & 5 \\
Ness & EDLC & Korea & carbon & Propylene & $2.5,2.7$ & $3-5000$ \\
Panasonic & Gold cap & Japan & & & $2.1-5.5$ & $0.022-70$ \\
ECOND & Super capacitor & Canada & & & $14-300$ & $11-160$ \\
\hline
\end{tabular}


improve the power density of the capacitor, but the energy density is significantly low. Hence, one of the great challenges in the development of EC technology is how to utilize the advantages of different types of carbon materials. Another challenge is the relatively high cost when compared to other energy devices. The cost of these novel nanostructures will be greatly cut down with the rapid development of nanotechnology, which is of great importance in their practical application.

The major direction for future research in this area lies in elaborately designing, controlling and tailoring the strategy to synthesize novel carbon-based composites, and to realize and exploit their more desirable functions for EC application. For example, all-solid-state EC is one of the trends for future research since the usage of liquid electrolyte has several drawbacks in the aspects of packaging and environment. Some research groups have already tried to fabricate EC with solid-state electrolyte through the assembly of CNT or graphene [104,105]. However, the performance of the all-solid-state EC can be improved further.

In conclusion, there is still tremendous room left for improvement in the design and fabrication of EC based on carbon nanostructures with high-performance electrochemical capacitance. It is believed that any breakthroughs in the area will facilitate the development of promising EC with a larger energy density, power density and more stable performance to bridge the gap of battery and conventional capacitors.

\section{Acknowledgements}

This work was supported by NSF/DOE Partnership in Plasma Science and Technology (NSF Grant No. CBET0853777 and DOE Grant No. DE-SC0001169). Authors would like to thank the PPPL Offsite Research Program supported by the Office of Fusion Energy Sciences for supporting arc experiments.

\section{REFERENCES}

[1] P. Simon and Y. Gogotsi, "Materials for Electrochemical Capacitors," Nature Materials, Vol. 7, No. 11, 2008, pp. 845-854. doi:10.1038/nmat2297

[2] M. Winter and R. J. Brodd, "What Are Batteries, Fuel Cells, and Supercapacitors?" Chemical Reviews, Vol. 104, No. 10, 2004, pp. 4245-4269. doi:10.1021/cr020730k

[3] L. L. Zhang and X. S. Zhao, "Carbon-Based Materials as Supercapacitor Electrodes," Chemical Society Reviews, Vol. 38, No. 9, 2009, pp. 2520-2531. doi:10.1039/b813846j

[4] Y. P. Zhai, Y. Q. Dou, D. Y. Zhao, P. F. Fulvio, R. T. Mayes and S. Dai, "Carbon Materials for Chemical Capacitive Energy Storage," Advanced Materials, Vol. 23, No. 42, 2011, pp. 4828-4850. doi:10.1002/adma.201100984
[5] A. Burke, "R \& D Considerations for the Performance and Application of Electrochemical Capacitors," Electrochimica Acta, Vol. 53, No. 3, 2007, pp. 1083-1091. doi:10.1016/i.electacta.2007.01.011

[6] R. Kotz and M. Carlen, "Principles and Applications of Electrochemical Capacitors," Electrochimica Acta, Vol. 45, No. 15-16, 2000, pp. 2483-2498. doi:10.1016/S0013-4686(00)00354-6

[7] J. R. Miller and P. Simon, "Electrochemical Capacitors for Energy Management," Science, Vol. 321, No. 5889, 2008, pp. 651-652. doi:10.1126/science.1158736

[8] D. N. Futaba, K. Hata, T. Yamada, T. Hiraoka, Y. Hayamizu, Y. Kakudate, O. Tanaike, H. Hatori, M. Yumura and S. Iijima, "Shape-Engineerable and Highly Densely Packed Single-Walled Carbon Nanotubes and Their Application as Super-Capacitor Electrodes," Nature Materials, Vol. 5, No. 12, 2006, pp. 987-994. doi:10.1038/nmat 1782

[9] J. Liu, G. Z. Cao, Z. G. Yang, D. H. Wang, D. Dubois, X. D. Zhou, G. L. Graff, L. R. Pederson and J. G. Zhang, "Oriented Nanostructures for Energy Conversion and Storage," ChemSusChem, Vol. 1, No. 8-9, 2008, pp. 676697. doi: $10.1002 /$ cssc. 200800087

[10] A. Du Pasquier, I. Plitz, S. Menocal and G. Amatucci, “A Comparative Study of Li-Ion Battery, Supercapacitor and Nonaqueous Asymmetric Hybrid Devices for Automotive Applications," Journal of Power Sources, Vol. 115, No. 1, 2003, pp. 171-178. doi:10.1016/S0378-7753(02)00718-8

[11] B. E. Conway, "Electrochemical Supercapacitors: Scientific Fundamentals and Technological Applications," Kluwer-Plenum, New York, 1999.

[12] J. M. Miller, "Ultracapacitor Applications," The Institution of Engineering and Technology, Stevenage, 2011.

[13] H. L. Wang, J. T. Robinson, G. Diankov and H. J. Dai, "Nanocrystal Growth on Graphene with Various Degrees of Oxidation," Journal of the American Chemical Society, Vol. 132, No. 10, 2010, pp. 3270-3271. doi:10.1021/ja100329d

[14] S. Iijima, "Helical Microtubules of Graphitic Carbon," Nature, Vol. 354, No. 6348, 1991, pp. 56-58. doi: $10.1038 / 354056 \mathrm{a} 0$

[15] K. S. Novoselov, A. K. Geim, S. V. Morozov, D. Jiang, Y. Zhang, S. V. Dubonos, I. V. Grigorieva and A. A. Firsov, "Electric Field Effect in Atomically Thin Carbon Films," Science, Vol. 306, No. 5696, 2004, pp. 666-669. doi:10.1126/science.1102896

[16] E. Frackowiak and F. Beguin, "Carbon Materials for the Electrochemical Storage of Energy in Capacitors," Carbon, Vol. 39, No. 6, 2001, pp. 937-950. doi:10.1016/S0008-6223(00)00183-4

[17] T. W. Ebbesen, H. J. Lezec, H. Hiura, J. W. Bennett, H. F. Ghaemi and T. Thio, "Electrical Conductivity of Individual Carbon Nanotubes," Nature, Vol. 382, No. 6586, 1996, pp. 54-56. doi:10.1038/382054a0

[18] Y. Wang, Z. Q. Shi, Y. Huang, Y. F. Ma, C. Y. Wang, M. M. Chen and Y. S. Chen, "Supercapacitor Devices Based on Graphene Materials," Journal of Physical Chemistry C, Vol. 113, No. 30, 2009, pp. 13103-13107. 


\section{doi:10.1021/jp902214f}

[19] H. V. Helmholtz, "Ueber einige Gesetze der Vertheilung elektrischer Ströme in körperlichen Leitern mit Anwendung auf die thierisch-elektrischen Versuche," $A n$ nalen der Physik, Vol. 165, No. 6, 1853, pp. 211-233. doi:10.1002/andp.18531650603

[20] O. Barbieri, M. Hahn, A. Herzog and R. Kotz, "Capacitance Limits of High Surface Area Activated Carbons for Double Layer Capacitors," Carbon, Vol. 43, No. 6, 2005, pp. 1303-1310. doi:10.1016/j.carbon.2005.01.001

[21] E. Raymundo-Pinero, K. Kierzek, J. Machnikowski and F. Beguin, "Relationship between the Nanoporous Texture of Activated Carbons and Their Capacitance Properties in Different Electrolytes," Carbon, Vol. 44, No. 12, 2006, pp. 2498-2507. doi:10.1016/j.carbon.2006.05.022

[22] K. S. W. Sing, D. H. Everett, R. A. W. Haul, L. Moscou, R. A. Pierotti, J. Rouquerol and T. Siemieniewska, "Reporting Physisorption Data for Gas Solid Systems with Special Reference to the Determination of Surface-Area and Porosity (Recommendations 1984)," Pure and Applied Chemistry, Vol. 57, No. 4, 1985, pp. 603-619. doi:10.1351/pac198557040603

[23] J. Chmiola, G. Yushin, Y. Gogotsi, C. Portet, P. Simon and P. L. Taberna, "Anomalous Increase in Carbon Capacitance at Pore Sizes Less than 1 Nanometer," Science, Vol. 313, No. 5794, 2006, pp. 1760-1763. doi:10.1126/science.1132195

[24] J. S. Huang, B. G. Sumpter and V. Meunier, "A Universal Model for Nanoporous Carbon Supercapacitors Applicable to Diverse Pore Regimes, Carbon Materials, and Electrolytes," Chemistry - A European Journal, Vol. 14, No. 22, 2008, pp. 6614-6626. doi:10.1002/chem.200800639

[25] J. S. Huang, B. G. Sumpter and V. Meunier, "Theoretical model for Nanoporous Carbon Supercapacitors," Angewandte Chemie-International Edition, Vol. 47, No. 3, 2008, pp. 520-524. doi:10.1002/anie.200703864

[26] N. L. Wu, "Nanocrystalline Oxide Supercapacitors," Materials Chemistry and Physics, Vol. 75, No. 1-3, 2002, pp. 6-11. doi:10.1016/S0254-0584(02)00022-6

[27] X. P. Dong, W. H. Shen, J. L. Gu, L. M. Xiong, Y. F. Zhu, $\mathrm{Z}$. Li and J. L. Shi, " $\mathrm{MnO}_{2}$-Embedded-in-MesoporousCarbon-Wall Structure for Use as Electrochemical Capacitors," Journal of Physical Chemistry B, Vol. 110, No. 12, 2006, pp. 6015-6019. doi:10.1021/jp056754n

[28] J. P. Zheng, P. J. Cygan and T. R. Jow, "Hydrous Ruthenium Oxide as an Electrode Material for Electrochemical Capacitors," Journal of the Electrochemical Society, Vol. 142, No. 8, 1995, pp. 2699-2703. doi:10.1149/1.2050077

[29] C. C. Hu, K. H. Chang, M. C. Lin and Y. T. Wu, "Design and Tailoring of the Nanotubular Arrayed Architecture of Hydrous $\mathrm{RuO}_{2}$ for Next Generation Supercapacitors," Nano Letters, Vol. 6, No. 12, 2006, pp. 2690-2695. doi:10.1021/n1061576a

[30] T. Brezesinski, J. Wang, S. H. Tolbert and B. Dunn, “Ordered Mesoporous Alpha- $\mathrm{MoO}_{3}$ with Iso-Oriented Nanocrystalline Walls for Thin-Film Pseudocapacitors," $\mathrm{Na}$ ture Materials, Vol. 9, No. 2, 2010, pp. 146-151. doi:10.1038/nmat 2612
[31] S. L. Xiong, C. Z. Yuan, M. F. Zhang, B. J. Xi and Y. T. Qian, "Controllable Synthesis of Mesoporous $\mathrm{Co}_{3} \mathrm{O}_{4} \mathrm{Na}-$ nostructures with Tunable Morphology for Application in Supercapacitors," Chemistry-A European Journal, Vol. 15, No. 21, 2009, pp. 5320-5326. doi:10.1002/chem.200802671

[32] S. Boukhalfa, K. Evanoff and G. Yushin, "Atomic Layer Deposition of Vanadium Oxide on Carbon Nanotubes for High-Power Supercapacitor Electrodes," Energy \& Environmental Science, Vol. 5, No. 5, 2012, pp. 6872-6879. doi:10.1039/C2EE21110F

[33] V. Subramanian, H. W. Zhu and B. Q. Wei, "Nanostructured $\mathrm{MnO}_{2}$ : Hydrothermal Synthesis and Electrochemical Properties as a Supercapacitor Electrode Material," Journal of Power Sources, Vol. 159, No. 1, 2006, pp. 361-364. doi:10.1016/j.jpowsour.2006.04.012

[34] Y. T. Wang, A. H. Lu, H. L. Zhang and W. C. Li, "Synthesis of Nanostructured Mesoporous Manganese Oxides with Three-Dimensional Frameworks and Their Application in Supercapacitors," Journal of Physical Chemistry C, Vol. 115, No. 13, 2011, pp. 5413-5421. doi:10.1021/jp110938x

[35] H. Y. Lee and J. B. Goodenough, "Supercapacitor Behavior with $\mathrm{KCl}$ Electrolyte," Journal of Solid State Chemistry, Vol. 144, No. 1, 1999, pp. 220-223. doi:10.1006/jssc. 1998.8128

[36] A. Rudge, J. Davey, I. Raistrick, S. Gottesfeld and J. P. Ferraris, "Conducting Polymers as Active Materials in Electrochemical Capacitors," Journal of Power Sources, Vol. 47, No. 1-2, 1994, pp. 89-107. doi:10.1016/0378-7753(94)80053-7

[37] K. Jurewicz, S. Delpeux, V. Bertagna, F. Beguin and E. Frackowiak, "Supercapacitors from Nanotubes/Polypyrrole Composites," Chemical Physics Letters, Vol. 347, No. 1-3, 2001, pp. 36-40. doi:10.1016/S0009-2614(01)01037-5

[38] H. Y. Mi, X. G. Zhang, X. G. Ye and S. D. Yang, "Preparation and Enhanced Capacitance of Core-Shell Polypyrrole/Polyaniline Composite Electrode for Supercapacitors," Journal of Power Sources, Vol. 176, No. 1, 2008, pp. 403-409. doi:10.1016/j.jpowsour.2007.10.070

[39] Y. G. Wang, H. Q. Li and Y. Y. Xia, "Ordered Whiskerlike Polyaniline Grown on the Surface of Mesoporous Carbon and Its Electrochemical Capacitance Performance," Advanced Materials, Vol. 18, No. 19, 2006, pp. 2619-2623. doi:10.1002/adma.200600445

[40] H. Y. Mi, X. G. Zhang, S. Y. An, X. G. Ye and S. D. Yang, "Microwave-Assisted Synthesis and Electrochemical Capacitance of Polyaniline/Multi-Wall Carbon Nanotubes Composite," Electrochemistry Communications, Vol. 9, No. 12, 2007, pp. 2859-2862. doi:10.1016/j.elecom.2007.10.013

[41] L. Chen, C. Z. Yuan, H. Dou, B. Gao, S. Y. Chen and X. G. Zhang, "Synthesis and Electrochemical Capacitance of Core-Shell Poly(3,4-ethylenedioxythiophene)/Poly(Sodium 4-Styrenesulfonate)-Modified Multiwalled Carbon Nanotube Nanocomposites," Electrochimica Acta, Vol. 54, No. 8, 2009, pp. 2335-2341. doi:10.1016/i.electacta.2008.10.071 
[42] K. H. An, K. K. Jeon, J. K. Heo, S. C. Lim, D. J. Bae and Y. H. Lee, "High-Capacitance Supercapacitor Using a Nanocomposite Electrode of Single-Walled Carbon Nanotube and Polypyrrole," Journal of the Electrochemical Society, Vol. 149, No. 8, 2002, pp. A1058-A1062. doi:10.1149/1.1491235

[43] C. Arbizzani, M. Mastragostino and F. Soavi, "New Trends in Electrochemical Supercapacitors," Journal of Power Sources, Vol. 100, No. 1-2, 2001, pp. 164-170. doi:10.1016/S0378-7753(01)00892-8

[44] E. Frackowiak, V. Khomenko, K. Jurewicz, K. Lota and F. Beguin, "Supercapacitors Based on Conducting Polymers/Nanotubes Composites," Journal of Power Sources, Vol. 153, No. 2, 2006, pp. 413-418. doi:10.1016/j.jpowsour.2005.05.030

[45] K. V. E. Frackowiak and F. Beguin, "Determination of the Specific Capacitance of Conducting Polymer/Nanotubes Composite Electrodes Using Different Cell Configurations," Electrochimica Acta, Vol. 50, No. 12, 2005, pp. 2499-2506. doi:10.1016/j.electacta.2004.10.078

[46] M. D. Stoller and R. S. Ruoff, "Best Practice Methods for Determining an Electrode Material's Performance for U1tracapacitors," Energy \& Environmental Science, Vol. 3, No. 9, 2010, pp. 1294-1301. doi:10.1039/C0EE00074D

[47] Z. C. Wu, Z. H. Chen, X. Du, J. M. Logan, J. Sippel, M. Nikolou, K. Kamaras, J. R. Reynolds, D. B. Tanner, A. F. Hebard and A. G. Rinzler, "Transparent, Conductive Carbon Nanotube Films," Science, Vol. 305, No. 5688, 2004, pp. 1273-1276. doi:10.1126/science. 1101243

[48] B. Dan, G. C. Irvin and M. Pasquali, "Continuous and Scalable Fabrication of Transparent Conducting Carbon Nanotube Films," ACS Nano, Vol. 3, No. 4, 2009, pp. 835-843. doi: $10.1021 / \mathrm{nn} 8008307$

[49] A. R. Boccaccini, J. Cho, J. A. Roether, B. J. C. Thomas, E. J. Minay and M. S. P. Shaffer, "Electrophoretic Deposition of Carbon Nanotubes," Carbon, Vol. 44, No. 15, 2006, pp. 3149-3160. doi:10.1016/j.carbon.2006.06.021

[50] D. H. Zhang, K. Ryu, X. L. Liu, E. Polikarpov, J. Ly, M. E. Tompson and C. W. Zhou, "Transparent, Conductive, and Flexible Carbon Nanotube Films and Their Application in Organic Light-Emitting Diodes," Nano Letters, Vol. 6, No. 9, 2006, pp. 1880-1886. doi: $10.1021 / \mathrm{n} 10608543$

[51] H. Gu and T. M. Swager, "Fabrication of Free-Standing, Conductive, and Transparent Carbon Nanotube Films," Advanced Materials, Vol. 20, No. 23, 2008, pp. 44334437. doi:10.1002/adma.200801062

[52] K. Flavin, I. Kopf, E. Del Canto, C. Navio, C. Bittencourt and S. Giordani, "Controlled Carboxylic Acid Introduction: A Route to Highly Purified Oxidised Single-Walled Carbon Nanotubes," Journal of Materials Chemistry, Vol. 21, No. 44, 2011, pp. 17881-17887. doi:10.1039/c1jm12217g

[53] J. Ge, G. H. Cheng and L. W. Chen, "Transparent and Flexible Electrodes and Supercapacitors Using Polyaniline/Single-Walled Carbon Nanotube Composite Thin Films," Nanoscale, Vol. 3, No. 8, 2011, pp. 3084-3088. doi:10.1039/c1nr10424a

[54] L. B. Hu, D. S. Hecht and G. Gruner, "Carbon Nanotube
Thin Films: Fabrication, Properties, and Applications," Chemical Reviews, Vol. 110, No. 10, 2010, pp. 57905844. doi:10.1021/cr9002962

[55] C. M. Niu, E. K. Sichel, R. Hoch, D. Moy and H. Tennent, "High Power Electrochemical Capacitors Based on Carbon Nanotube Electrodes," Applied Physics Letters, Vol. 70, No. 11, 1997, pp. 1480-1482. doi:10.1063/1.118568

[56] K. H. An, W. S. Kim, Y. S. Park, Y. C. Choi, S. M. Lee, D. C. Chung, D. J. Bae, S. C. Lim and Y. H. Lee, "Supercapacitors Using Single-Walled Carbon Nanotube Electrodes," Advanced Materials, Vol. 13, No. 7, 2001, pp. 497-500.

doi:10.1002/1521-4095(200104)13:7<497::AID-ADMA4 97>3.0.CO;2-H

[57] T. Kitano, Y. Maeda and T. Akasaka, "Preparation of Transparent and Conductive Thin Films of Carbon Nanotubes Using a Spreading/Coating Technique," Carbon, Vol. 47, No. 15, 2009, pp. 3559-3565. doi:10.1016/j.carbon.2009.08.027

[58] L. B. Hu, H. Wu and Y. Cui, "Printed Energy Storage Devices by Integration of Electrodes and Separators into Single Sheets of Paper," Applied Physics Letters, Vol. 96, No. 18, 2010, Article ID: 183502. doi:10.1063/1.3425767

[59] L. B. Hu, J. W. Choi, Y. Yang, S. Jeong, F. La Mantia, L. F. Cui and Y. Cui, "Highly Conductive Paper for EnergyStorage Devices," Proceedings of the National Academy of Sciences of the United States of America, Vol. 106, No. 51, 2009, pp. 21490-21494. doi:10.1073/pnas.0908858106

[60] J. Cho, K. Konopka, K. Rozniatowski, E. Garcia-Lecina, M. S. P. Shaffer and A. R. Boccaccini, "Characterisation of Carbon Nanotube Films Deposited by Electrophoretic Deposition," Carbon, Vol. 47, No. 1, 2009, pp. 58-67. doi:10.1016/j.carbon.2008.08.028

[61] S. F. Pei, J. H. Du, Y. Zeng, C. Liu and H. M. Cheng, "The Fabrication of a Carbon Nanotube Transparent Conductive Film by Electrophoretic Deposition and Hot-Pressing Transfer," Nanotechnology, Vol. 20, No. 23, 2009, Article ID: 235707.

[62] C. S. Du and N. Pan, "High Power Density Supercapacitor Electrodes of Carbon Nanotube Films by Electrophoretic Deposition," Nanotechnology, Vol. 17, No. 21, 2006, pp. 5314-5318. doi:10.1088/0957-4484/17/21/005

[63] S. S. Fan, M. G. Chapline, N. R. Franklin, T. W. Tombler, A. M. Cassell and H. J. Dai, "Self-Oriented Regular Arrays of Carbon Nanotubes and Their Field Emission Properties," Science, Vol. 283, No. 5401, 1999, pp. 512-514. doi:10.1126/science.283.5401.512

[64] K. Hata, D. N. Futaba, K. Mizuno, T. Namai, M. Yumura and S. Iijima, "Water-Assisted Highly Efficient Synthesis of Impurity-Free Single-Walled Carbon Nanotubes," $A b$ stracts of Papers of the American Chemical Society, Vol. 229, No. 5700, 2005, pp. U967-U967. doi:10.1126/science. 1104962

[65] J. Kong, H. T. Soh, A. M. Cassell, C. F. Quate and H. J. Dai, "Synthesis of Individual Single-Walled Carbon Nanotubes on Patterned Silicon Wafers," Nature, Vol. 395, No. 6705, 1998, pp. 878-881. doi:10.1038/27632

[66] A. Ural, Y. M. Li and H. J. Dai, "Electric-Field-Aligned 
Growth of Single-Walled Carbon Nanotubes on Surfaces," Applied Physics Letters, Vol. 81, No. 18, 2002, pp. 3464-3466. doi:10.1063/1.1518773

[67] S. Han, X. L. Liu and C. W. Zhou, "Template-Free Directional Growth of Single-Walled Carbon Nanotubes on aand r-Plane Sapphire," Journal of the American Chemical Society, Vol. 127, No. 15, 2005, pp. 5294-5295. doi:10.1021/ja042544x

[68] S. J. Kang, C. Kocabas, T. Ozel, M. Shim, N. Pimparkar, M. A. Alam, S. V. Rotkin and J. A. Rogers, "High-Performance Electronics Using Dense, Perfectly Aligned Arrays of Single-Walled Carbon Nanotubes," Nature Nanotechnology, Vol. 2, No. 4, 2007, pp. 230-236. doi:10.1038/nnano.2007.77

[69] R. N. Das, B. Liu, J. R. Reynolds and A. G. Rinzler, "Engineered Macroporosity in Single-Wall Carbon Nanotube Films," Nano Letters, Vol. 9, No. 2, 2009, pp. 677-683. doi:10.1021/n1803168s

[70] A. Izadi-Najafabadi, S. Yasuda, K. Kobashi, T. Yamada, D. N. Futaba, H. Hatori, M. Yumura, S. Iijima and K. Hata, "Extracting the Full Potential of Single-Walled Carbon Nanotubes as Durable Supercapacitor Electrodes Operable at $4 \mathrm{~V}$ with High Power and Energy Density," Advanced Materials, Vol. 22, No. 35, 2010, pp. E235E241. doi:10.1002/adma.200904349

[71] B. Kim, H. Chung and W. Kim, "High-Performance Supercapacitors Based on Vertically Aligned Carbon Nanotubes and Nonaqueous Electrolytes," Nanotechnology, Vol. 23, No. 15, 2012, Article ID: 155401. doi:10.1088/0957-4484/23/15/155401

[72] M. Toupin, T. Brousse and D. Belanger, "Charge Storage Mechanism of $\mathrm{MnO}_{2}$ Electrode Used in Aqueous Electrochemical Capacitor," Chemistry of Materials, Vol. 16, No. 16, 2004, pp. 3184-3190. doi:10.1021/cm049649j

[73] X. Zhao, C. Johnston and P. S. Grant, "A Novel Hybrid Supercapacitor with a Carbon Nanotube Cathode and an Iron Oxide/Carbon Nanotube Composite Anode," Journal of Materials Chemistry, Vol. 19, No. 46, 2009, pp. 87558760. doi:10.1039/b909779a

[74] R. F. Zhou, C. Z. Meng, F. Zhu, Q. Q. Li, C. H. Liu, S. S. Fan and K. L. Jiang, "High-Performance Supercapacitors Using a Nanoporous Current Collector Made from Super-Aligned Carbon Nanotubes," Nanotechnology, Vol. 21, No. 34, 2010, Article ID: 345701. doi:10.1088/0957-4484/21/34/345701

[75] S. L. Chou, J. Z. Wang, S. Y. Chew, H. K. Liu and S. X. Dou, "Electrodeposition of $\mathrm{MnO}_{2}$ Nanowires on Carbon Nanotube Paper as Free-Standing, Flexible Electrode for Supercapacitors," Electrochemistry Communications, Vol. 10, No. 11, 2008, pp. 1724-1727. doi:10.1016/j.elecom.2008.08.051

[76] P. C. Chen, G. Z. Shen, Y. Shi, H. T. Chen and C. W. Zhou, "Preparation and Characterization of Flexible Asymmetric Supercapacitors Based on Transition-Metal-Oxide Nanowire/Single-Walled Carbon Nanotube Hybrid ThinFilm Electrodes," Acs Nano, Vol. 4, No. 8, 2010, pp. 4403-4411. doi:10.1021/nn100856y

[77] M. D. Stoller, S. J. Park, Y. W. Zhu, J. H. An and R. S. Ruoff, "Graphene-Based Ultracapacitors," Nano Letters,
Vol. 8, No. 10, 2008, pp. 3498-3502. doi: $10.1021 / \mathrm{n} 1802558 \mathrm{y}$

[78] H. A. Becerril, J. Mao, Z. Liu, R. M. Stoltenberg, Z. Bao and Y. Chen, "Evaluation of Solution-Processed Reduced Graphene Oxide Films as Transparent Conductors," ACS Nano, Vol. 2, No. 3, 2008, pp. 463-470. doi: $10.1021 / \mathrm{nn} 700375 \mathrm{n}$

[79] O. Volotskova, I. Levchenko, A. Shashurin, Y. Raitses, K. Ostrikov and M. Keidar, "Single-Step Synthesis and Magnetic Separation of Graphene and Carbon Nanotubes in Arc Discharge Plasmas," Nanoscale, Vol. 2, No. 10, 2010, pp. 2281-2285. doi:10.1039/c0nr00416b

[80] M. Eizenberg and J. M. Blakely, "Carbon Monolayer Phase Condensation on Ni(111)," Surface Science, Vol. 82 , No. 1, 1979, pp. 228-236. doi:10.1016/0039-6028(79)90330-3

[81] X. S. Li, W. W. Cai, J. H. An, S. Kim, J. Nah, D. X. Yang, R. Piner, A. Velamakanni, I. Jung, E. Tutuc, S. K. Banerjee, L. Colombo and R. S. Ruoff, "Large-Area Synthesis of High-Quality and Uniform Graphene Films on Copper Foils," Science, Vol. 324, No. 5932, 2009, pp. 1312-1314. doi:10.1126/science. 1171245

[82] S. Stankovich, R. D. Piner, S. T. Nguyen and R. S. Ruoff, "Synthesis and Exfoliation of Isocyanate-Treated Graphene Oxide Nanoplatelets," Carbon, Vol. 44, No. 15, 2006, pp. 3342-3347. doi:10.1016/j.carbon.2006.06.004

[83] A. Reina, X. T. Jia, J. Ho, D. Nezich, H. B. Son, V. Bulovic, M. S. Dresselhaus and J. Kong, "Large Area, FewLayer Graphene Films on Arbitrary Substrates by Chemical Vapor Deposition," Nano Letters, Vol. 9, No. 1, 2009, pp. 30-35. doi: $10.1021 / \mathrm{n} 1801827 \mathrm{~V}$

[84] M. J. Allen, V. C. Tung and R. B. Kaner, "Honeycomb Carbon: A Review of Graphene," Chemical Reviews, Vol. 110, No. 1, 2010, pp. 132-145. doi:10.1021/cr900070d

[85] A. Srivastava, C. Galande, L. Ci, L. Song, C. Rai, D. Jariwala, K. F. Kelly and P. M. Ajayan, "Novel Liquid Precursor-Based Facile Synthesis of Large-Area Continuous, Single, and Few-Layer Graphene Films," Chemistry of Materials, Vol. 22, No. 11, 2010, pp. 3457-3461. doi: $10.1021 / \mathrm{cm} 101027 \mathrm{c}$

[86] J. J. Yoo, K. Balakrishnan, J. S. Huang, V. Meunier, B. G. Sumpter, A. Srivastava, M. Conway, A. L. M. Reddy, J. $\mathrm{Yu}$, R. Vajtai and P. M. Ajayan, "Ultrathin Planar Graphene Supercapacitors," Nano Letters, Vol. 11, No. 4, 2011, pp. 1423-1427. doi:10.1021/nl200225j

[87] W. S. Hummers and R. E. Offeman, "Preparation of Graphitic Oxide," Journal of the American Chemical Society, Vol. 80, No. 6, 1958, pp. 1339-1339. doi:10.1021/ja01539a017

[88] Y. W. Zhu, S. Murali, M. D. Stoller, K. J. Ganesh, W. W. Cai, P. J. Ferreira, A. Pirkle, R. M. Wallace, K. A. Cychosz, M. Thommes, D. Su, E. A. Stach and R. S. Ruoff, "Carbon-Based Supercapacitors Produced by Activation of Graphene," Science, Vol. 332, No. 6037, 2011, pp. 1537-1541. doi: $10.1126 /$ science. 1200770

[89] C. G. Liu, Z. N. Yu, D. Neff, A. Zhamu and B. Z. Jang, "Graphene-Based Supercapacitor with an Ultrahigh Energy Density," Nano Letters, Vol. 10, No. 12, 2010, pp. 4863-4868. doi:10.1021/nl102661q 
[90] V. Strong, S. Dubin, M. F. El-Kady, A. Lech, Y. Wang, B. H. Weiller and R. B. Kaner, "Patterning and Electronic Tuning of Laser Scribed Graphene for Flexible All-Carbon Devices," ACS Nano, Vol. 6, No. 2, 2012, pp. 13951403. doi: $10.1021 / \mathrm{nn} 204200 \mathrm{w}$

[91] M. F. El-Kady, V. Strong, S. Dubin and R. B. Kaner, "Laser Scribing of High-Performance and Flexible Graphene-Based Electrochemical Capacitors," Science, Vol. 335, No. 6074, 2012, pp. 1326-1330. doi:10.1126/science. 1216744

[92] Q. Cheng, J. Tang, J. Ma, H. Zhang, N. Shinya and L. C. Qin, "Graphene and Nanostructured $\mathrm{MnO}_{2}$ Composite Electrodes for Supercapacitors," Carbon, Vol. 49, No. 9, 2011, pp. 2917-2925. doi:10.1016/j.carbon.2011.02.068

[93] Q. Wu, Y. X. Xu, Z. Y. Yao, A. R. Liu and G. Q. Shi, "Supercapacitors Based on Flexible Graphene/Polyaniline Nanofiber Composite Films," ACS Nano, Vol. 4, No. 4, 2010, pp. 1963-1970. doi:10.1021/nn1000035

[94] V. C. Tung, L. M. Chen, M. J. Allen, J. K. Wassei, K. Nelson, R. B. Kaner and Y. Yang, "Low-Temperature Solution Processing of Graphene-Carbon Nanotube Hybrid Materials for High-Performance Transparent Conductors," Nano Letters, Vol. 9, No. 5, 2009, pp. 19491955. doi:10.1021/n19001525

[95] Q. Cheng, J. Tang, J. Ma, H. Zhang, N. Shinya and L. C. Qin, "Graphene and Carbon Nanotube Composite Electrodes for Supercapacitors with Ultra-High Energy Density," Physical Chemistry Chemical Physics, Vol. 13, No. 39, 2011, pp. 17615-17624. doi:10.1039/c1cp21910c

[96] M. Keidar, A. Shashurin, J. A. Li, O. Volotskova, M. Kundrapu and T. Sen Zhuang, "Arc Plasma Synthesis of Car- bon Nanostructures: Where Is the Frontier?" Journal of Physics D-Applied Physics, Vol. 44, No. 17, 2011, Article ID: 174006. doi:10.1088/0022-3727/44/17/174006

[97] M. Keidar, I. Levchenko, T. Arbel, M. Alexander, A. M. Waas and K. Ostrikov, "Increasing the Length of SingleWall Carbon Nanotubes in a Magnetically Enhanced Arc Discharge," Applied Physics Letters, Vol. 92, No. 4, 2008, Article ID: 043129. doi:10.1063/1.2839609
[98] O. Volotskova, J. A. Fagan, J. Y. Huh, F. R. Phelan, A. Shashurin and M. Keidar, "Tailored Distribution of Single-Wall Carbon Nanotubes from Arc Plasma Synthesis Using Magnetic Fields," ACS Nano, Vol. 4, No. 9, 2010, pp. 5187-5192. doi:10.1021/nn101279r

[99] M. Keidar, I. Levchenko, T. Arbel, M. Alexander, A. M. Waas and K. K. Ostrikov, "Magnetic-Field-Enhanced Synthesis of Single-Wall Carbon Nanotubes in Arc Discharge," Journal of Applied Physics, Vol. 103, No. 9, 2008, Article ID: 094318. doi:10.1063/1.2919712

[100] J. Li, O. Volotskova, A. Shashurin and M. Keidar, "Controlling Diameter Distribution of Catalyst Nanoparticles in Arc Discharge," Journal of Nanoscience and Nanotechnology, Vol. 11, No. 11, 2011, pp. 10047-10052. doi:10.1166/jnn.2011.4999

[101] J. Li, O. Volotskova, A. Shashurin and M. Keidar, "Correlation between Formation of the Plasma Jet and Synthesis of Graphene in Arc Discharge," IEEE Transactions on plasma Science, Vol. 39, No. 11, 2011, pp. 2366-2367. doi:10.1109/TPS.2011.2160567

[102] J. Li, A. Shashurin, M. Kundrapu and M. Keidar, "Simultaneous Synthesis of Single Wall Carbon Nanotubes and Graphene in a Magnetically-Enhanced Arc Plasma," Journal of Visualized Experiments, Vol. 60, 2012, p. e3455. doi: $10.3791 / 3455$

[103] J. Li, X. Cheng, J. Sun, M. Reeves, A. Shashurin and M. Keidar, "Preparation of Resistance Controlled Electrodes of a Paper Based Capacitor with Carbon Nanotubes Graphene Composites in Magnetically Enhanced Arc Discharge," Unpublished.

[104] S. Hu, R. Rajamani and X. Yu, "Flexible Solid-State Paper Based Carbon Nanotube Supercapacitor," Applied Physics Letters, Vol. 100, No. 10, 2012, Article ID: 104103. doi:10.1063/1.3691948

[105] B. G. Choi, J. Hong, W. H. Hong, P. T. Hammond and H. Park, "Facilitated Ion Transport in All-Solid-State Flexible Supercapacitors," ACS Nano, Vol. 5, No. 9, 2011, pp. 7205-7213. doi:10.1021/nn202020w 